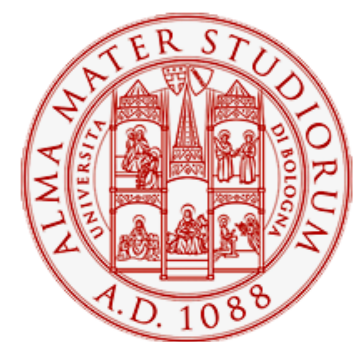

Alma Mater Studiorum - Università di Bologna DEPARTMENT OF ECONOMICS

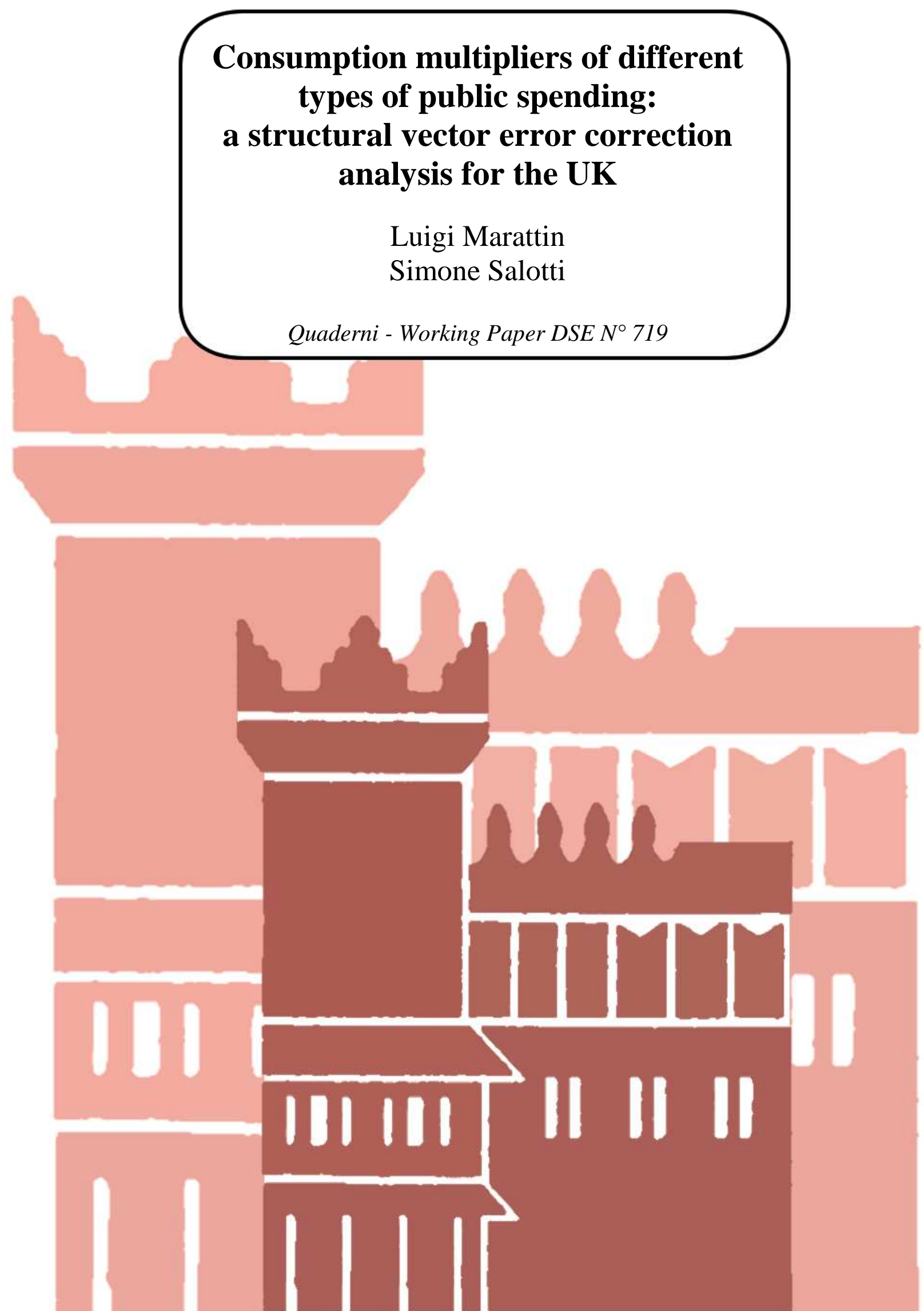




\title{
Consumption multipliers of different types of public spending: a structural vector error correction analysis for the UK
}

Luigi Marattin

Department of Economics, University of Bologna, Strada Maggiore 45, 40125 Bologna (Italy)

+390512092606

luigi.marattin@unibo.it

Simone Salotti

Department of Economics, National University of Ireland, Galway, University Road, Galway (Ireland)

+353091493053

simone.salotti@nuigalway.ie

We thank all the participants to the 2011 Annual Conference of the Scottish Economic Society for useful comments. A previous version of this paper was circulated under the title "The response of private consumption to different public spending categories: VAR evidence for the UK": we thank all the participants to the Ecomod 2010 conference and to the Department of Economics seminar in Bologna in November 2009 for useful comments on that version. All remaining errors are our responsibility.

\section{This version: $14 / 05 / 2011$}

\begin{abstract}
The aim of this paper is to investigate the relationship between government spending and private consumption in the UK, for which there is scarce previous empirical evidence. We disaggregate public expenditure into three categories and search for the corresponding private consumption multipliers. Our analysis includes the estimation of a structural vector error correction model, using quarterly non-interpolated data for the period 1981:1 - 2007:4. Initially, we estimate negative (and barely significant) effects on consumption of shocks to total public spending. Then, using the spending breaking down, we find that while shocks to public wages crowd-out private consumption as predicted by neoclassical models, shocks to the non-systematic component of social spending and government purchases of goods and services generate a positive reaction, so to crowd-in private consumption. Thus, the qualitative and quantitative dimensions of fiscal multipliers on private consumption change across different public spending categories. Our findings suggest that any empirical support of competing theoretical models on the issue would benefit from a disaggregation of government expenditure, rather than focusing on the aggregate measure.
\end{abstract}

Keywords: Fiscal policy, Cointegration, Structural VECM, Subset SVECM.

JEL classification: E62, H30. 


\section{Introduction}

At the beginning of 2009, when the need to implement an unprecedented increase in public spending to counteract the global recession became clear, a common question among policy makers and Treasury Departments all over the world was the following: which part of public expenditure should we privilege in order to maximize the positive effect on private demand? Two years later, as the agenda is dominated by the need of fiscal retrenchment, the question is reversed: what should be cut first in order not to dampen the recovery? In both cases, the issue to be addressed is the same: finding the public expenditure category associated with the highest consumption multiplier. Attempts to evaluate the effectiveness of fiscal policy often rely on the appraisal of the sign and magnitude of public expenditure's impact either on GDP (e.g. Blanchard and Perotti 2002), or private consumption (e.g. García and Ramajo 2005), or on private investment (e.g. Wang 2005). In our paper we investigate the private consumption multiplier associated not only with aggregate government spending, but also with each of its three different components, namely wage, non-wage and social security expenditures (see Figure 1).

\section{FIGURE 1 ABOUT HERE}

These three spending categories differ in many respects, so it is reasonably plausible to hypothesize different qualitative and quantitative impacts on private consumption. The fundamental motivation of our work is the belief that a focus on the aggregate measure of public spending, rather than on a more accurate disaggregation, might imply inaccurate policy conclusions on its stimulating role (if any). Particularly, we explicitly consider government social expenditure as a spending category per se, rather than including it into the revenue component as usually done in the literature. The rationale for that relies in our desire to verify the consumption-enhancing properties of income redistribution, which is implemented through the net social security transfers.

Our empirical analysis is based on a structural vector error correction (SVEC) model using UK quarterly non-interpolated data (1981:Q1 -2007:Q4). At the moment the evidence on this country is scarce, as only few studies have employed UK data (Perotti 2004 and 2007, Ramos and Roca-Sagales 2008, Monacelli and Perotti 2010). Moreover - as all of them adopted VAR estimations - none of them addressed the cointegrating properties of the series under investigation. In particular, for the period 
1981-2001, Monacelli and Perotti (2010) find mixed results on the effects of government spending on private consumption, with positive effects when using the GDP deflator and negative effects when using own deflators. ${ }^{1}$ Investigating a similar period, Perotti (2004) finds that the cumulated response of consumption to a $1 \%$ of GDP government spending shock after three years is merely $+.05 \%$ of GDP. Finally, with data up to 2005, Ramos and Roca-Sagales (2008) find that government spending negatively affects GDP. ${ }^{2}$ Our aim is to shed light on these few (and mixed) results analyzing UK data using a methodology which innovates in several aspects. First of all, we investigate public spending using both its aggregate measure and each of its components. This marks a difference with what has been done in the literature so far (Beetsma et al. 2006 and 2008, Giordano et al. 2007, Cavallo 2005 and 2007), as we explicitly consider net social security spending in the analysis instead of including it into the net taxes variable. Then, we use a cointegrating framework that permits to extract information from the series under investigation taking into account their long run properties, in a spirit close to Krusec (2003) who estimated a SVEC model of fiscal policy using US data. Differently from him, we include public debt in the model, following Favero and Giavazzi (2007).

Our results show that shocks to aggregate public spending negatively affect private consumption, even if the estimates are barely statistically different from zero at standard levels. Looking at the effects of the three components of public spending, we find that shocks to both net social security transfers and government "pure" consumption (purchases of goods and services) result in positive responses of private consumption. While the response to the first shock lasts four years, the response to the second shock dies out within six quarters. On the other hand, shocks to public wages negatively affect private consumption, with effects that die out less than two years after the shock. These results support the intuition that using total government spending does not seem to be a reasonable simplification when studying the effects of public spending on private consumption.

We believe these results to be relevant for the theoretical debate between alternative and competing approaches modelling private consumption's impact of fiscal shocks. In particular, the standard neoclassical real business cycle (RBC) model predicts a fall in consumption following a government

\footnotetext{
${ }^{1}$ In fact, the consumption impulse responses show that, even when using the GDP deflator, the cumulated response of private consumption is circa zero 16 quarters after the public spending shock (ten quarters after the shock the effects become negative, similarly to what Perotti 2007 finds investigating a larger time span).

${ }^{2}$ There are other studies of the UK fiscal policy (e.g. Sawyer 2007, Budd 2010), but their scopes are different from the one of quantifying the effects of public spending on GDP or on some components of aggregate demand.
} 
spending shock, because of the Ricardian equivalence: higher public spending must be matched by an equivalent increase in taxation in present discounted terms. Thus, intertemporal optimizing consumers suffer from a negative wealth effect that decreases consumption (with positive effects on output due to the increased labour supply triggered by the wealth effect). Since virtually no study seems to confirm the prediction of the standard neoclassical model (as pointed out by Galí et al. 2007), New Keynesian economists attempted to reconcile theory with empirical evidence by rescuing a consumption-enhancing role for fiscal policy. This has been accomplished either using finite-horizons frameworks (Blanchard 1985) or introducing credit-constrained agents and rule-of-thumb consumers (Mankiw 2000, Galí et al. 2004 and 2007, Coenen and Straub 2005).3 Above all, this latter approach has gained considerable attention. It assumes that there is a fraction of non-Ricardian households who do not optimize over the life cycle and are thus forced to consume out of current income, so that their consumption responds promptly to a fiscal policy impulse.4 A further research strand explicitly considers the per se government expenditure's impact on consumption. This is often carried out by an ad-hoc utility function specification where private and public consumption are entered in a non-additive form, so to obtain a non-zero impact of one on the marginal utility of the other (Bouakez and Rebei 2003).

Our study can be relevant for all the above-mentioned theoretical discussions. We provide evidence that considering aggregate government spending can indeed be misleading. The identification of social expenditure and pure consumption as the sole expenditure categories which are effective in stimulating private consumption leads to two remarks. First, the complementarity/substitutability issue cannot be discussed independently from a sufficient disaggregation of government spending. Second, the rule-of thumb-consumers approach can indeed be justified no longer on the assumption of an exogenous fraction of credit constrained agents. For instance, it could be hypothesized that the consumption of the beneficiaries of social security transfers (presumably lying in the lower part of income distribution) is

3 As a matter of fact, there are also alternative ways to the same result. Ravn et al. (2004) obtain a positive effect on consumption without credit-constrained agents, but assuming that the representative individual forms consumption habits on the individual variety in a monopolistic competition setting, rather than on aggregate consumption. Corsetti et al. (2009) use spending reversals to get a positive response of private consumption to government spending shocks.

4 As discussed by Galí et al. (2007), the presence of non-Ricardian consumers must be coupled with sticky prices and imperfectly competitive markets in order to obtain a private consumption's positive response. 
stimulated by at least one component of public spending, thus the rule-of-thumb models could be parameterized accordingly.

The remainder of this paper is organized as follows. Section 2 presents the theory behind the SVEC methodology. Section 3 contains the estimates of the VEC model. Section 4 deals with the structural analysis (identification assumptions and impulse response analysis). Section 5 concludes and discusses some policy implications.

\section{The SVEC methodology}

The literature that investigates the effects of public spending on private consumption and output has largely used structural VAR models since the seminal article by Blanchard and Perotti (2002) on the US economy. In our paper we use a closely related technique: a SVEC model that takes into account the cointegrating properties of the series under investigation. The analysis starts from a reduced form VEC model:

$$
\Delta y_{t}=\alpha \beta^{\prime} y_{t-1}+\Gamma_{1} \Delta y_{t-1}+\ldots+\Gamma_{p-1} \Delta y_{t-p+1}+D_{t}+u_{t}
$$

where $y_{t}$ is a $K x 1$ vector of time series, $D_{t}$ is a vector of deterministic terms, and $\Gamma_{1}, \ldots, \Gamma_{\mathrm{p}-1}$ are $K x K$ coefficient matrices. The reduced form disturbance (forecast error) $u_{t}$ is a $K x 1$ unobservable zero mean white noise process with covariance matrix $\Sigma_{\mathrm{u}} . \alpha$ and $\beta$ are $K \mathrm{x} r$ matrices containing the loading coefficients and the $r$ cointegrating vectors, respectively. We are interested in the effects of fundamental shocks $\varepsilon_{\mathrm{t}}$ (error terms of the structural form VEC model) on the system variables $y_{t .}$. The link between the two errors is given by the contemporaneous impact matrix $A$ :

$$
u_{t}=A \varepsilon_{t}
$$

In order to analyze the effects of the underlying structural shocks we need to identify the $A$ matrix, by recovering its $K^{2}$ elements. Assuming that the structural shocks are uncorrelated and have unit variances $\left(\Sigma_{\varepsilon}=\mathrm{I}_{\mathrm{k}}\right)$ we get:

$$
\sum_{u}=E\left[u_{t} u_{t}^{\prime}\right]=E\left[\varepsilon_{t} \varepsilon_{t}^{\prime}\right]=A \sum_{\varepsilon} A^{\prime}=A A^{\prime}
$$

The symmetry of $\Sigma_{\varepsilon}$ and the normalization of the structural variances impose $K(K+1) / 2$ restrictions on the $K^{2}$ parameters of $A$. Therefore, to exactly identify the elements of $A$, we need to impose $K(K-1) / 2$ 
additional linearly independent restrictions. We prefer to impose long run restrictions rather than contemporaneous restrictions, which are usually harder to justify even with quarterly data. From Granger's representation theorem (Johansen, 1995) it follows that the long run effects of structural shocks $\varepsilon_{\mathrm{t}}$ can be written as:

$$
C(1) A
$$

where $C(1)$ is the total impact matrix computed as:

$$
C(1)=\beta \perp\left(\alpha \perp^{\prime}\left(I_{K}-\sum_{i=1}^{p-1} \Gamma_{i}\right) \beta \perp\right)^{-1} \alpha \perp^{\prime}
$$

$\beta^{\perp}$ and $\alpha^{\perp}$ represent the orthogonal complements of $\beta$ and $\alpha$ respectively. Note that $C(1)$ has reduced rank $r k(C(1))=K-r$. Long run restrictions can now be imposed by setting elements of (2.4). As in the common trends literature (e.g. see King et al. 1991), we distinguish between permanent and transitory effects. Setting elements of (2.4) to zero and replacing $C(1)$ by an estimator obtained from the reduced form, the restrictions may be written in implicit form as:

$$
R_{l} \operatorname{vec}(\hat{C}(1) A)=R_{l}\left(I_{k} x \hat{C}(1)\right) \operatorname{vec}(A)=R_{l}^{*} \operatorname{vec}(A)=0
$$

where $R_{l}$ is an appropriate restriction matrix. These long run restrictions can be combined with contemporaneous restrictions on the elements of A. With enough identifying restrictions, estimates of the contemporaneous impact matrix can be found by maximizing the concentrated log-likelihood function with respect to the free structural parameters (see e.g. Breitung et al. 2004). Concentrating the log-likelihood with respect to the reduced form parameters is no longer possible if additional restrictions for $\alpha, \Gamma_{1}, \ldots, \Gamma_{\mathrm{p}-1}$ are imposed. Nevertheless, residuals from a subset VEC model may still give a reasonable estimate of $\Sigma_{\mathrm{u}}$ (Hamilton, 1994). Thus, the same estimation technique as before can be used to form reasonable estimates for $A$.

Based on this discussion, the econometric analysis of the UK fiscal policy effects will be the following: first, we determine the cointegration rank of the system of interest, imposing over-identifying restrictions on the cointegrating vectors using the Johansen (1995) method. These cointegrating relations are used to setup a full VEC model, where no further restrictions are imposed. Residuals from the full and subset VEC model are used to form estimates for $\Sigma_{\mathrm{u}}$. Second, long run and contemporaneous 
restrictions are used to form estimates of $A$. Using the estimated contemporaneous impact matrix, we recover the structural shocks and we analyze their impact through an impulse response analysis.

\section{Analysis of UK public expenditure}

The present section opens our empirical analysis on the UK economy. Particularly, it is concerned with the description and discussion of the dataset (subsection 3.1), the investigation of the cointegrating properties (subsection 3.2), and the estimation of the VEC model (subsection 3.3).

\subsection{Data description}

"The availability of quarterly fiscal variables represents the main constraint for the analysis of fiscal policy with VAR models" (Giordano et al. 2007, p. 710). Furthermore, Perotti (2004) correctly warns against the distortions coming from the usage of quarterly data set obtained by interpolation of yearly values. This remark makes the data availability constraint even more binding, and poses considerable limitations to the implementation of a fully-equipped large scale time series analysis. We have chosen to sacrifice the generality of our empirical results in favour of a complete non-interpolated quarterly dataset. We use UK data from the first quarter of 1981 to the last quarter of 2007 taken from the OECD Economic Outlook no. 83.5 We use the following variables: the log of real government wage expenditure $G W_{t}$, the log of real government net social security spending (cyclically adjusted) $G S S_{t}$, the $\log$ of real government spending in goods and services $G C_{t}$, the $\log$ of real government consumption (calculated as the sum of the three previous variables), the log of real total government consumption, $G T O T_{t}$, the $\log$ of real taxes (cyclically adjusted) $T_{t}$, the $\log$ of real private consumption $C_{t}$, and the $\log$ of real government net financial liabilities $B_{t}$. The time series are shown in Figure 2. The details on the construction of the fiscal variables used in the system and some descriptive statistics are given in the Appendix. We do not include public investment into the analysis as this component implies external effects, such as production externalities, that are not immediately associated with private consumption, which is the focus of this paper (see e.g. Mittnik and Neumann 2001). We also do not explicitly consider

\footnotetext{
5 The quarterly data of the Economic Outlook are normally obtained by interpolation, but not those of the UK. The beginning of the period has been chosen because of the strong evidence for a structural break in UK data between 1981 and the previous period (Perotti, 2004).
} 
tax shocks, as they are particularly hard to identify in a SVAR model (Perotti, 2007, Alesina and Ardagna 2009). Also, differently from previous analysis, we do not consider net taxes (revenues minus transfers), rather we differentiate between social security contributions and revenues coming both from direct and indirect taxes. Both series are cyclically adjusted, since both are likely to be determined by the business cycles and we want to control for it.

\section{INSERT FIGURE 2 ABOUT HERE}

\subsection{Unit root and cointegration analysis}

This subsection deals with the integration properties of the seven time series. The results of unit root tests are reported in Table 1. The standard augmented Dickey-Fuller (ADF) test is performed for all the series. In all tests the specification of the deterministic term and the lag order are important and may determine the test result, as it is usually the case. Therefore, in some cases we report tests for different sets of deterministic terms and lag orders. The latter are chosen by the Akaike and Hannan-Quinn criteria (AIC and HQ respectively, see Lütkepohl, 1991) using a maximum lag order of ten. For the results in Table 1 it can be inferred that all the variables are integrated of order one $(I(1))$.

\section{INSERT TABLE 1 ABOUT HERE}

The cointegration properties of all the endogenous $I(1)$ variables were investigated by Johansen's trace tests (as in, e.g., Pesaran and Shin 2002). They are likelihood ratio (LR) tests based on reduced rank regressions of the corresponding VEC models. Suitable critical values depend on the deterministic terms included in the test regression (see Johansen, 1995). The test results for different systems of interest in the context of our analysis are reported in Table 2. We used the AIC, SC and HQ information criteria

(the latter two always suggested to use the same number of lags) to determine the lag length of the processes, reported in the table.

INSERT TABLE 2 ABOUT HERE 
The difference among the four systems investigated in Table 2 lies in the public spending variable, which in turn is total consumption GTOT, wages $G W$, net social security spending $G S S$, and purchases of goods and services GC. Results show that in three of the four systems there appear to be two cointegrating relationships (all but that including government wages). It is standard to use theoretical considerations as a guidance to express meaningful long-run relationships (Lütkepohl and Krätzig 2004, Pesaran and Shin 2002): the first relationship is between taxes and both government spending and public debt. It arises from the fact that in the long run, when the real stock of government debt is constant, total government expenditures including interest payments on the outstanding debt must equal government revenues in the form of taxes. The second relationship is between private consumption and both government spending and public debt. This comes from the standard flexible prices models that imply that any change in public spending - and, via the government budget constraint, in the stock of debt - has a long-run impact on private consumption through the Ricardian equivalence. The increase in the present value of future taxation triggers a negative wealth effect that decreases private components of aggregate demand. Finally, since there are no theoretical justifications to the different number of cointegrating relations in the four investigated systems, we carry out the analysis assuming that the cointegrating rank is equal to 2 for all of them.

\subsection{VECM estimation results}

The four models have been estimated with the number of lags chosen so that at least one year of observations was included (i.e. with three lagged differences). ${ }^{6}$ LM tests do not indicate the presence of residual autocorrelation in the models. All diagnostics results are reported in the Appendix, together with the VECM estimates which come from subset models estimated by applying the top-down procedure based on the AIC (see Brüggemann and Lütkepohl, 2001). The top-down algorithm is a sequential elimination procedure that minimizes the chosen information criterion by imposing zero restrictions so to reduce the number of estimated parameters.

We report the estimated cointegrating matrix $\beta$ in Table 3 together with the estimated loading coefficients.

\footnotetext{
6 “The reason for overruling information criteria in the empirical literature and mechanically opting for four lags goes back to Blanchard and Perotti (2002). In their paper the goal was to capture seasonal patterns in the collection of taxes by allowing for quarter dependence, hence, the four lags" (Hauzenberger, 2010, 8).
} 


\section{INSERT TABLE 3 ABOUT HERE}

Looking at the estimated cointegrating relationships, there are few variables that present different estimated signs of their coefficients across the four specifications. As for the first relationship (taxes on the left-hand side, government spending and debt on the right-hand side), positive coefficients are associated with debt independently from the type of public spending included. On the other hand, we estimate positive coefficients for all the government spending variables with the exception of the one on net social security spending. This finding suggests that in our sample the government intertemporal budget constraint did not bind in case of social spending (that is, it did not require per se to be backed-up by increased revenues). As for the second estimated cointegrating relation (consumption on the left-hand side, public spending and debt on the right-hand side), negative coefficients are associated with debt in all four models. Again, the net social security spending specification differs from the others, since in this case a positive coefficient is associated to public spending, while negative coefficients are estimated in the other specifications. We read this peculiarity as indicating the consumption-stimulating role of social expenditure. This might be regarded as evidence of the presence of credit-constrained consumers (à la Galí et al. 2007) who rely on social transfers to sustain their consumption dynamics. However, we turn to the structural analysis in order to understand the (possibly) different effects of the various components of public spending.

\section{Structural analysis}

In this section we derive identifying restrictions according to the discussion in Section 2 to exactly identify the structural shocks. Then, we carry out the analysis using impulse response functions.

\subsection{Identification procedure}

From Section 2 we know that we need $K(K-1) / 2=4(4-1) / 2=6$ additional linearly independent restrictions coming from economic theory to exactly identify the structural shocks. In addition, we know from the common trends literature that in a four-dimensional system with two cointegrating relations, 10 
only two shocks can have permanent effects. We therefore restrict shocks to $T_{t}$ and $G_{t}$ (all of the four public spending variables considered, depending on the specification) to have no permanent effects on any of the variables of the system, since standard models do not envisage any long-run effects for these variables. This implies that shocks $\varepsilon_{\mathrm{T}, \mathrm{t}}$, and $\varepsilon_{\mathrm{G}, \mathrm{t}}$ do not have permanent effects on the system variables, which can be expressed as zero columns in $C(1) A$ (due to the chosen ordering of the variables: $C_{t}, T_{t}, G_{t}$, $\left.B_{t}\right):$

$$
C(1) A=\left(\begin{array}{llll}
* & 0 & 0 & * \\
* & 0 & 0 & * \\
* & 0 & 0 & * \\
* & 0 & 0 & *
\end{array}\right)
$$

These 8 zero restrictions only corresponds to 4 linearly independent restrictions, due to the reduced rank of the matrix. Therefore, we need 2 additional restrictions, 1 of which must be imposed in $C(1) A$, while the other must be included in the contemporaneous relations matrix (Lütkepohl and Krätzig 2004). Thus, we assume that consumption shocks have no long run effects on debt and that taxes do not contemporaneously (within the quarter) affect public spending. The reason for the first restriction is that, according to the standard steady-state formulation of the government budget constraint, the long run value of the debt does not depend on private consumption, but rather on the levels of the primary deficits and the real interest rate.

The reason for assuming no contemporaneous effects of tax shocks on government spending (the restriction in the contemporaneous relations matrix) regards the political economy of budget processing (Beetsma and Bovenberg 1998) which makes very unlikely a quarterly revision of predetermined spending categories on the basis of unexpected movements in tax collection. As a robustness test, we tried a different (meaningful) alternative zero contemporaneous restriction: we assumed no contemporaneous effects of government spending on taxes. The results are substantially unaffected, with the only effect being a stronger negative response of private consumption to public wages shocks. Therefore, the chosen identification strategy can be expressed as follows: 


$$
A=\left(\begin{array}{cccc}
* & * & * & * \\
* & * & * & * \\
* & 0 & * & * \\
* & * & * & *
\end{array}\right), C(1) A=\left(\begin{array}{cccc}
* & 0 & 0 & * \\
* & 0 & 0 & * \\
* & 0 & 0 & * \\
0 & 0 & 0 & *
\end{array}\right)
$$

The four just-identified structural VEC models are estimated with the method illustrated in Section 2 (see the detailed results in the Appendix, Tables A2-A7).

\subsection{Impulse response analysis}

Impulse responses are shown for the four estimated SVEC models. Only public spending shocks are considered, as they are the main focus of the analysis. 95\% confidence intervals for the impulse responses are bootstrapped (Breitung et al. 2004) using the percentile method proposed by Hall (1992). The responses have to be interpreted as responses to one standard deviation shocks of the public spending variable (we report in parenthesis the quantitative effects assuming that shocks are equal to $1 \%$ of the spending variable below). Figure 3 shows the responses of all the variables of the model to a total government spending shock.

\section{INSERT FIGURE 3 ABOUT HERE}

Although the response of private consumption is negative (one year cumulative impact: $-0.53 \%$ ), it is barely significantly different from zero at standard levels (the 95\% confidence interval does not include zero for the second quarter after the shock only). We view this result as a confirmation of the previous literature findings for the UK, where most estimates are either quantitatively unimportant or negative. Note that both Perotti (2004, 2007) and Monacelli and Perotti (2010) use data up to 2000, Ramos and Roca-Sagales (2008) up to 2005, while we extend the time period under investigation to the end of 2007. We turn now to the analysis of the impulse responses generated by the SVEC models that include the three components of public spending separately (see Figures 4-6).

\section{INSERT FIGURES 4-6 ABOUT HERE}


Government wages shocks negatively affect private consumption with a one-year cumulative impact equal to $-0.51 \%$. These negative effects die out within six quarters. On the other hand, both government consumption and net social security transfers have positive private consumption multipliers, with oneyear cumulative impact equal to, respectively, $+0.53 \%$ and $+0.57 \%$. Particularly, the stimulating role of social spending seems to be confirmed by its remarkable persistence, as its effects remain positive and significant up to four years after the initial shock (much longer than in the case of government consumption).

Our results seem to depict a general framework featured by a slight flavour of both old and New Keynesian theories. The fact that the government consumption multiplier is positive and higher than that attached to the wage expenditure (which is even negative) seems to confirm the traditional Keynesian intuition on the role played by the marginal propensity to consume in determining the size of the different multipliers. Nevertheless, this remark should also imply a lower value of the social spending multipliers, being itself an income subsidy and therefore subject to the same "limitations" of the wage multiplier, as far as the impact on consumption is concerned. However, a possible explanation of the importance and positive sign of the estimated social spending multiplier can be found in one of the more recent New Keynesian contributions, namely the rule-of-thumb-consumers approach. As mentioned in the introduction, the inclusion of the social expenditure category into the model can help identifying more closely the credit-constrained agents, which might actually coincide with the receptors of social transfers. Those households, being forced to consume out of their current income (which presumably largely relies on social transfers), increase consumption in response to that kind of government spending stimulus. On the other hand, the negative sign of the multiplier associated to the wage expenditure lies firmly within the RBC approach, which predicts a crowding-out effect of private consumption after a government spending stimulus.

Overall, the results confirm the intuitions about the different roles played by different components of public spending: not only the signs of the responses change depending on the analyzed component, but also the persistence of the shocks varies across the three different public spending categories.

\section{Conclusions}

Our paper aims at providing a more accurate understanding of the effects of public spending on private consumption, analyzing the different effects associated to three categories of expenditure, namely wages, social security expenditure, and pure consumption. In order to accomplish this task we perform 
an empirical analysis focused on the UK economy, as previous literature on this country contains scarce and ambiguous evidence. We employ a SVEC model with an identification strategy that takes advantage

of the differentiation between permanent and temporary shocks in the cointegrating framework. Our results conform to the previous evidence when using public spending in its aggregate, as we estimate negative effects on private consumption which are barely different from zero at standard confidence levels (Perotti 2004 and 2007, Ramos and Roca-Sagales 2008, Monacelli and Perotti 2010). Interesting insights come from the estimation of the model using the three components of public spending, since we find that shocks to both net social security transfers and government pure consumption result in positive responses of private consumption. While the response to the first one lasts for a long period of time with significant effects up to four years from the shock, the response to the pure consumption shock dies out within six quarters. This consumption-enhancing role of fiscal policy is envisaged in New Keynesian models. On the other hand, shocks to public wages negatively affect private consumption (as predicted by standard RBC models), with effects that die out within two years after the shock. These results support the intuition that using total aggregate government expenditure does not seem to be a reasonable simplification when studying the effects of public spending on private consumption. While we believe that this analysis can represent a useful contribution to a more effective management of fiscal policy tools on the expenditure side, the general validity of the findings is certainly limited by the focus on a single country. A panel analysis on European Union countries would allow a more complete answer to our original question and would probably be the best next step to be taken.

\section{References}

Alesina AF, Ardagna S (2009) Large changes in fiscal policy: taxes versus spending. NBER wp

Beetsma RMWJ, Bovenberg AL (1998) Monetary union without fiscal coordination may discipline policymakers. J Int Econ 45:239-258

Beetsma RMWJ, Giuliodori M, Klaassen F (2006) Trade spill-overs of fiscal policy in the European Union: a panel analysis. Econ Pol 21(48):639-687

Beetsma RMWJ, Klaassen F, Giuliodori M (2008) The effects of public spending shocks on trade balances and budget deficits in the European Union. JEEA 6(2-3):414-423

Blanchard O (1985) Debt, deficits and finite horizons. J Polit Economy 93(2):223-247 
Blanchard O, Perotti R (2002) An empirical characterisation of the dynamic effects of changes in government spending and taxes on output. Quart J Econ117(4):1329-1368

Bouakez H, Rebei N (2003) Why does private consumption rises after a government spending shock? Bank of Canada wp

Breitung J, Brüggemann R, Lütkepohl H (2004) Structural vector autoregressive modeling and impulse responses. In:

Lütkepohl H, Krätzig M (ed) Applied time series econometrics. Cambridge University Press, pp 159-196

Brüggemann R, Lütkepohl H (2001) Lag selection in subset VAR models with an application to a U.S. monetary system. In:

Frohn J, Friedman R (ed) Econometric studies: a festschrift in honour of Joachim Frohn. LIT Verlag Münster

Budd A (2010) Fiscal policy under labour. Nat Inst Econ Rev 212:R34-R48

Cavallo M (2005) Government employment expenditure and the effects of fiscal policy shocks. Fed Res Bank of San Francisco

Cavallo M (2007) Government consumption expenditure and the current account. PFM 7:73-115

Coenen G, Straub R (2005) Does government spending crowd in private consumption? Theory and empirical evidence for the Euro area. Int Finance 8(3):435-470

Corsetti G, Meier A, Müller G (2009) Fiscal stimulus with spending reversals. IMF wp 09/106

Davidson R, MacKinnon J (1993) Estimation and inference in econometrics. Oxford University Press, London

Favero CA, Giavazzi F (2007) Debt and the effects of fiscal policy. NBER wp

Galí J, López-Salido JD, Vallés J (2004) Rule-of-thumb consumers and the design of interest rate rules. J Money, Credit, Banking 36(4):739-764

Galí J, López-Salido JD, Vallés J (2007) Understanding the effects of government spending on consumption. JEEA 5(1):227270

García A, Ramajo J (2005) Fiscal policy and private consumption behaviour: the Spanish case. Empirical Econ30:115-135

Giordano R, Momigliano S, Neri S., Perotti R (2007) The effects of fiscal policy in Italy: evidence from a VAR model. Europ J Polit Economy 23(3):707-733

Hall P (1992) The bootstrap and Edgeworth expansion. Springer, New York

Hamilton JD (1994) Time series analysis. University Press Princeton, New Jersey

Hauzenberger K (2010) Flexible regime-switching projections to estimate the dynamic effects of a government spending stimulus. European University Institute wp, Florence

Johansen, S. (1995). Likelihood-based inference in cointegrated vector autoregressive models. Oxford University Press.

King RG, Plosser CI, Stock JH, Watson M (1991) Stochastic trends and economic fluctuations. Amer Econ Rev 81(4):819840

Krusec D (2003) The effects of fiscal policy on output in a structural VEC model framework: the case of four EMU and four non-EMU OECD countries. European University Institute wp, Florence

Lütkepohl H (1991) Introduction to multiple time series analysis. Berlin: Springer-Verlag

Lütkepohl H, Krätzig M (2004) Applied time series econometrics. Cambridge Univ Pr

Mankiw NG (2000) The savers-spenders theory of fiscal policy. Amer Econ Rev 90:120-125

Mittnik S., Neuman T (2001) Dynamic effects of public investment: vector autoregressive evidence from six industrialized countries. Empirical Econ 26:429-446 
Monacelli T, Perotti R (2010) Fiscal policy, the real exchange rate and traded goods. Economic J 120(544):437-461

Perotti R (2004) Estimating the effects of fiscal policy on OECD countries. IGIER-Bocconi wp

Perotti R (2007) In search of the transmission mechanism of fiscal policy. NBER wp 13143

Pesaran MH, Shin Y (2002) Long-run structural modelling. Economet Rev 21(1):49-87

Ramos X, Roca-Sagales O (2008) Long-term effects of fiscal policy on the size and distribution of the pie in the UK. Fisc stud 29(3):387-411

Ravn M, Schmitt-Grohè S, Uribe M (2004) Deep habits. Rev Econ Stud 73:195-218

Sawyer M (2007) Fiscal policy under New Labour. Cambridge J Econ 31:885-899

Wang B (2005) Effects of government expenditure on private investment: Canadian empirical evidence. Empirical Econ 30:493-504

Wilcox D (1989) The sustainability of government deficits: implications of the present value borrowing constraint. J Money,

Credit, Banking 21:291-306 


\section{Figures}

Figure 1: The three components of public spending in the UK

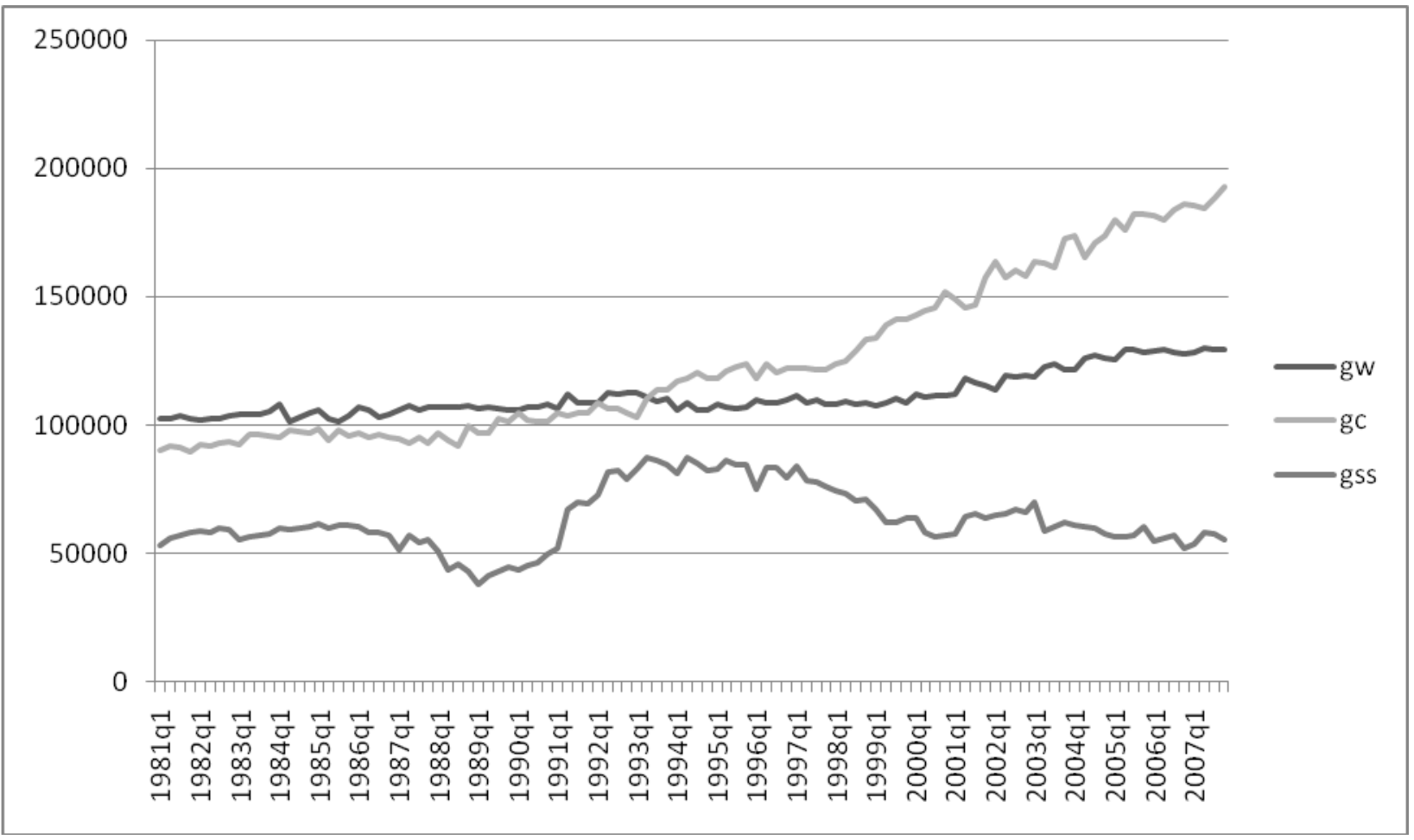

Source: OECD quarterly Economic Outlook 83, own computations. 
Figure 2: The data

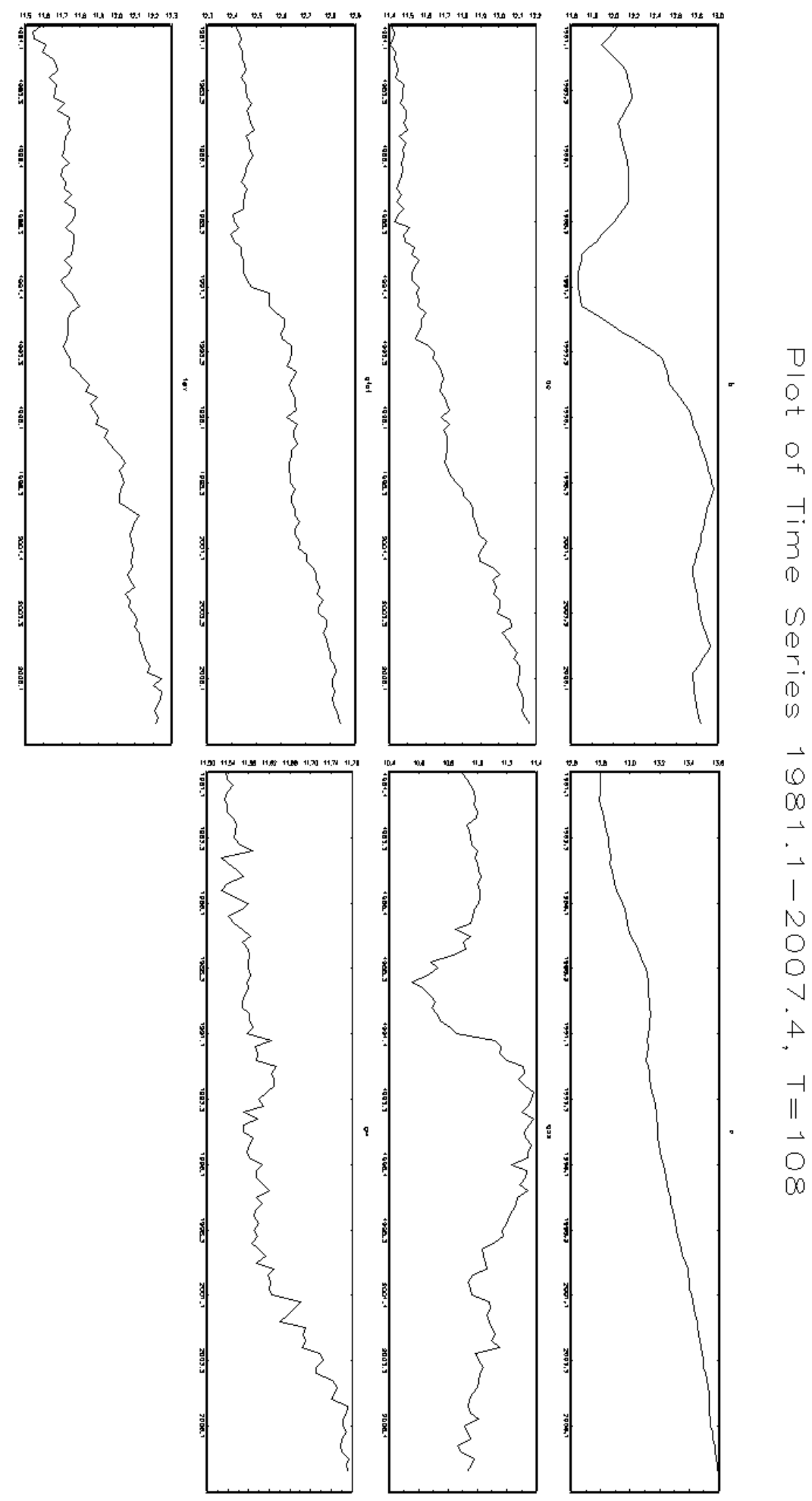

Source: OECD quarterly Economic Outlook no. 83, authors' calculations. 
Figure 3: SVEC impulse responses - total government spending model

JMulTi Fri Oet 29 12:21:14 2010

SVEC Impulse Responses
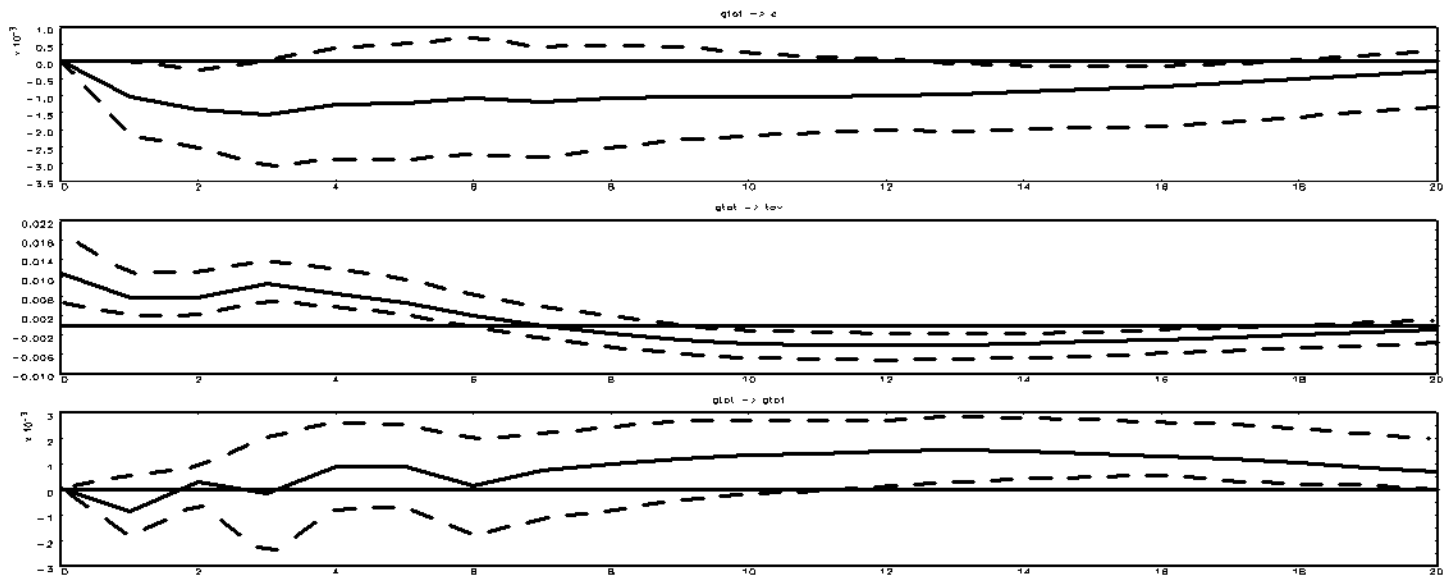

$\rightarrow$ at $\rightarrow$ b

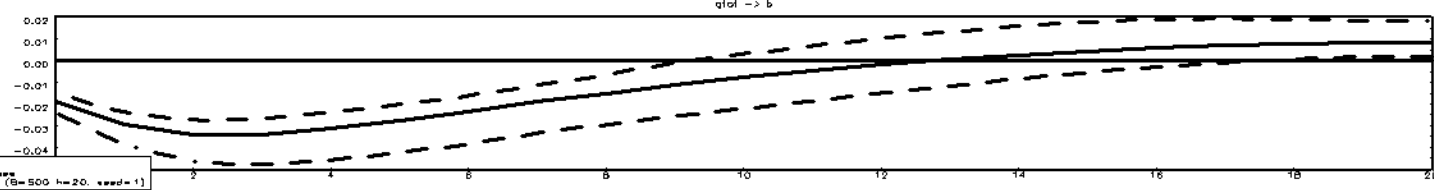

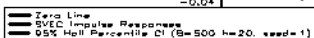

Notes: $95 \%$ confidence bands are bootstrapped using the Hall method with 500 replications.

Figure 4: SVEC impulse responses - government wages model

JMulTi Fri Oet $29 \quad 12: 23: 14 \quad 2010$

SVEC Impulse Responses
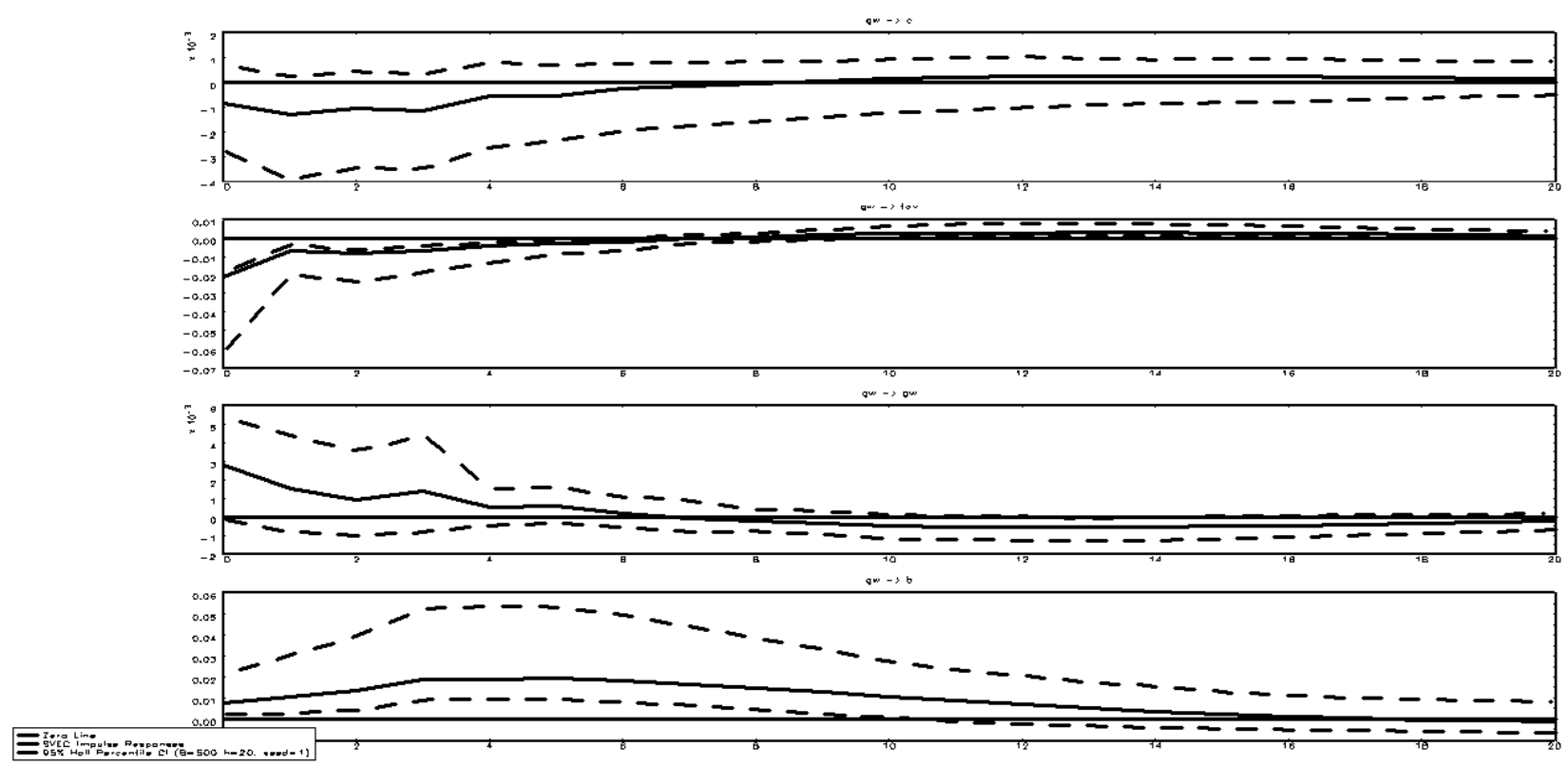

Notes: 95\% confidence bands are bootstrapped using the Hall method with 500 replications. 
Figure 5: SVEC impulse responses - net social security expenditure model

JMulTi Fri Oet $29 \quad 12: 30: 58 \quad 2010$

SVEC Impulse Responses

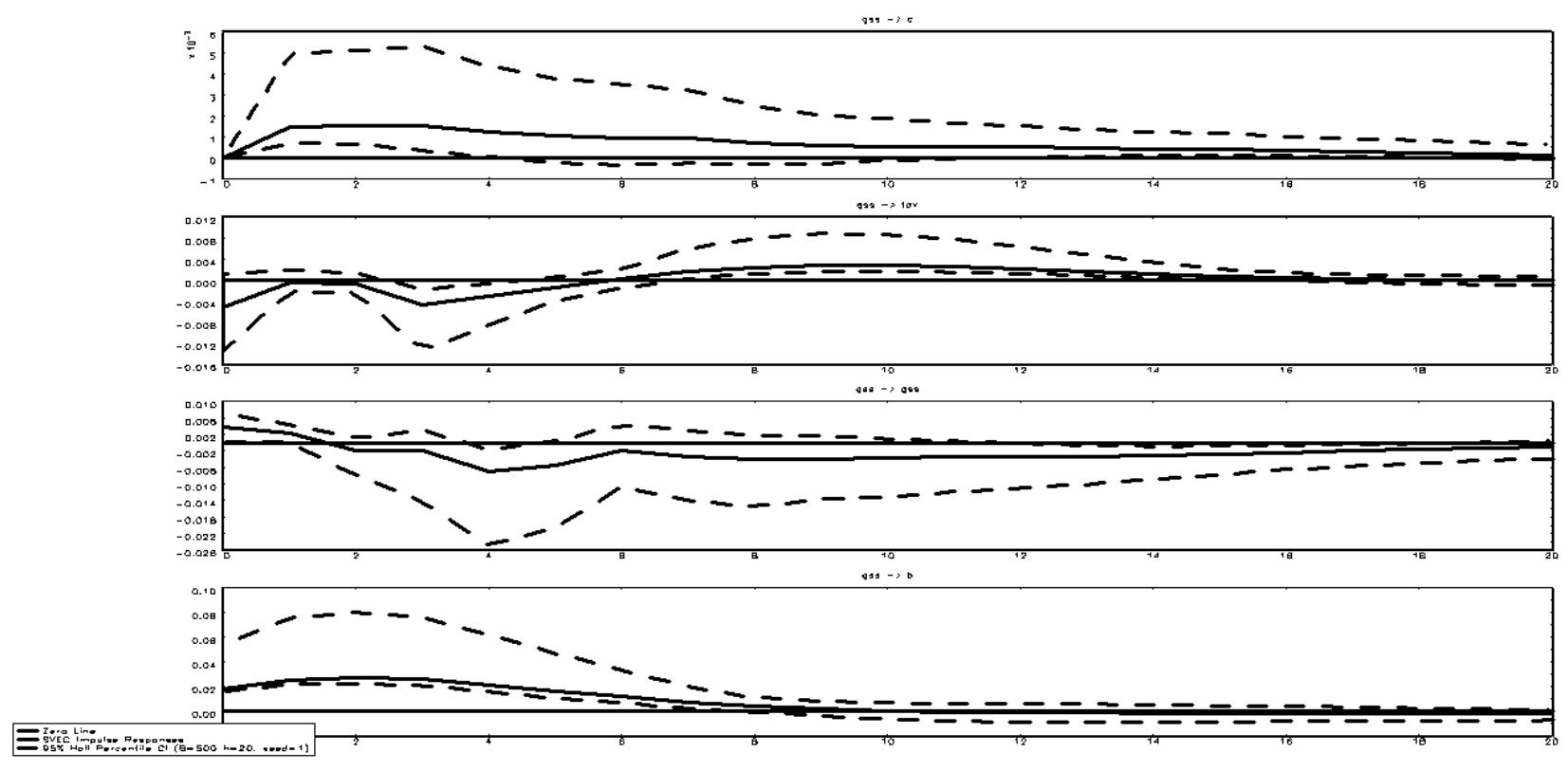

Notes: $95 \%$ confidence bands are bootstrapped using the Hall method with 500 replications.

Figure 6: SVEC impulse responses - government consumption model

JMulTi Fri Oct $29 \quad 12: 37: 28 \quad 2010$

SVEC Impulse Responses
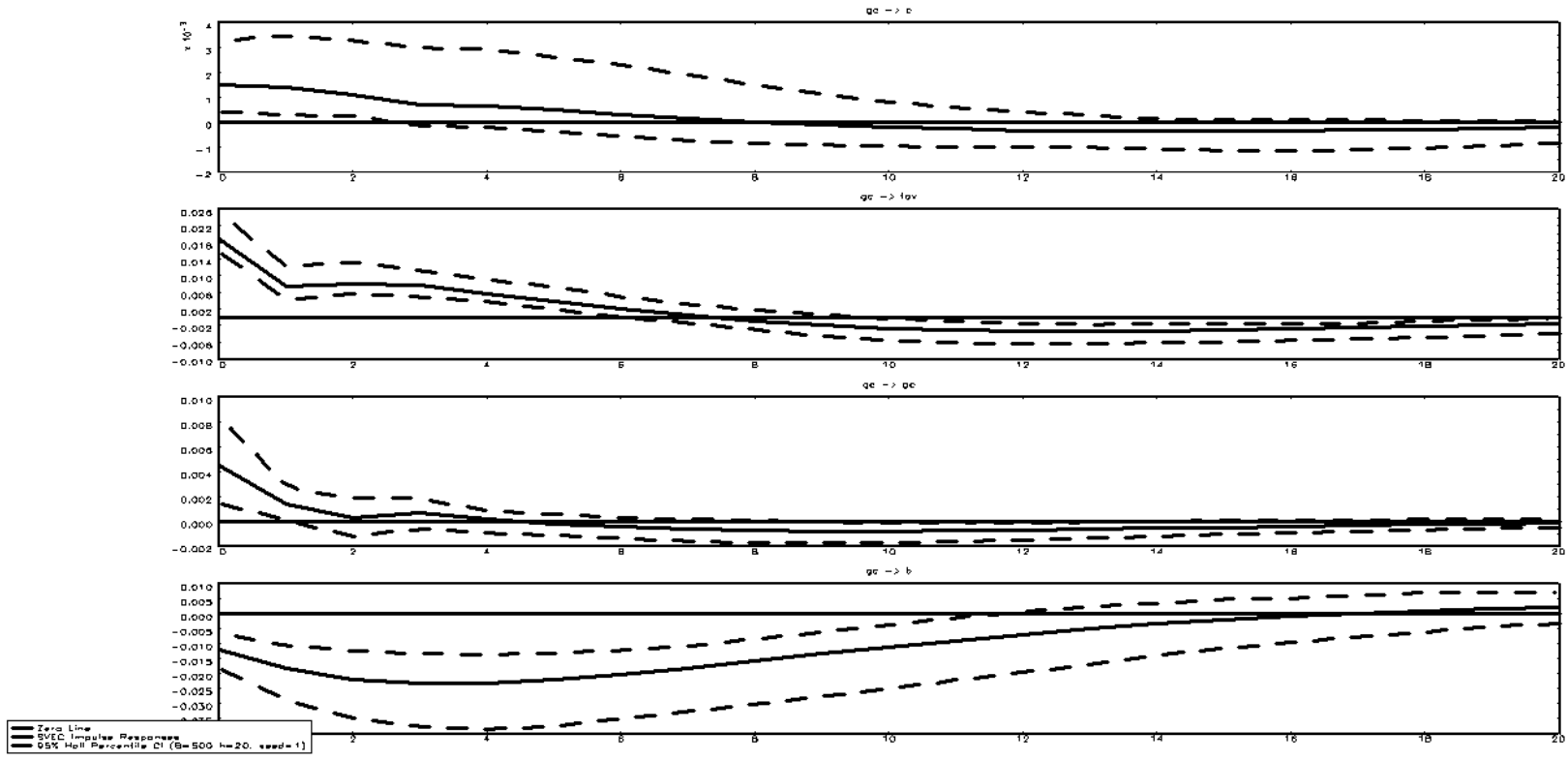

Notes: $95 \%$ confidence bands are bootstrapped using the Hall method with 500 replications.

20 


\section{Tables}

Table 1: Unit root tests for sample period 1981:1 to 2007:4

\begin{tabular}{|c|c|c|c|c|}
\hline Variable & Deterministic terms & Lags & Test statistic & $5 \%$ crit. value \\
\hline $\mathrm{GWt}$ & $\mathrm{C}, \mathrm{T}$ & $\mathrm{n}(\mathrm{AIC})=\mathrm{n}(\mathrm{HQ})=5$ & -1.3688 & -3.41 \\
\hline$\Delta \mathrm{GWt}$ & $\mathrm{C}$ & $\mathrm{n}(\mathrm{AIC})=\mathrm{n}(\mathrm{HQ})=4$ & $-3.862 * *$ & -2.86 \\
\hline \multirow[t]{2}{*}{ GSSt } & $\mathrm{C}$ & $\mathrm{n}(\mathrm{AIC})=5$ & -2.43 & -2.86 \\
\hline & $\mathrm{C}$ & $\mathrm{n}(\mathrm{HQ})=0$ & -1.62 & -2.86 \\
\hline \multirow[t]{2}{*}{$\mathrm{GCt}$} & $\mathrm{C}, \mathrm{T}, \mathrm{SD}$ & $\mathrm{n}(\mathrm{AIC})=2$ & -1.71 & -3.41 \\
\hline & $\mathrm{C}, \mathrm{T}, \mathrm{SD}$ & $\mathrm{n}(\mathrm{HQ})=1$ & -1.94 & -3.41 \\
\hline$\Delta \mathrm{GCt}$ & $\mathrm{C}, \mathrm{T}$ & $\mathrm{n}(\mathrm{AIC})=\mathrm{n}(\mathrm{HQ})=1$ & $-10.32 * *$ & -3.41 \\
\hline GTOTt & $\mathrm{C}, \mathrm{T}$ & $\mathrm{n}(\mathrm{AIC})=8$ & $-3.48 *$ & -3.41 \\
\hline$\Delta \mathrm{GTOTt}$ & & $\mathrm{n}(\mathrm{HQ})=0$ & $-12.95 * *$ & -2.86 \\
\hline $\mathrm{Tt}$ & $\mathrm{C}, \mathrm{T}$ & $\mathrm{n}(\mathrm{AIC})=\mathrm{n}(\mathrm{HQ})=1$ & -1.88 & -3.41 \\
\hline$\Delta \mathrm{Tt}$ & $\mathrm{C}$ & $\mathrm{n}(\mathrm{AIC})=\mathrm{n}(\mathrm{HQ})=0$ & $-15.47 * *$ & -2.86 \\
\hline $\mathrm{Ct}$ & $\mathrm{C}, \mathrm{T}$ & $\mathrm{n}(\mathrm{AIC})=\mathrm{n}(\mathrm{HQ})=3$ & -2.59 & -3.41 \\
\hline \multirow[t]{2}{*}{$\Delta \mathrm{Ct}$} & $\mathrm{C}$ & $\mathrm{n}(\mathrm{AIC})=2$ & $-3.71 * *$ & -2.86 \\
\hline & $\mathrm{C}$ & $\mathrm{n}(\mathrm{HQ})=1$ & $4.50 * *$ & -2.86 \\
\hline $\mathrm{Bt}$ & $\mathrm{C}$ & $\mathrm{n}(\mathrm{AIC})=\mathrm{n}(\mathrm{HQ})=1$ & -1.56 & -2.86 \\
\hline
\end{tabular}

Notes: C - constant, T - linear time trend, SD - seasonal dummies. n(AIC) and n(HQ) are the lag orders recommended by the AIC and HQ criteria, respectively, when the maximum lag order is set to 8. ADF critical values from Davidson and MacKinnon (1993). * and ** indicate that the null hypothesis of a unit root can be rejected at the 5\% and $1 \%$, respectively. 
Table 2: Cointegration tests for sample period 1981:1 to 2007:4

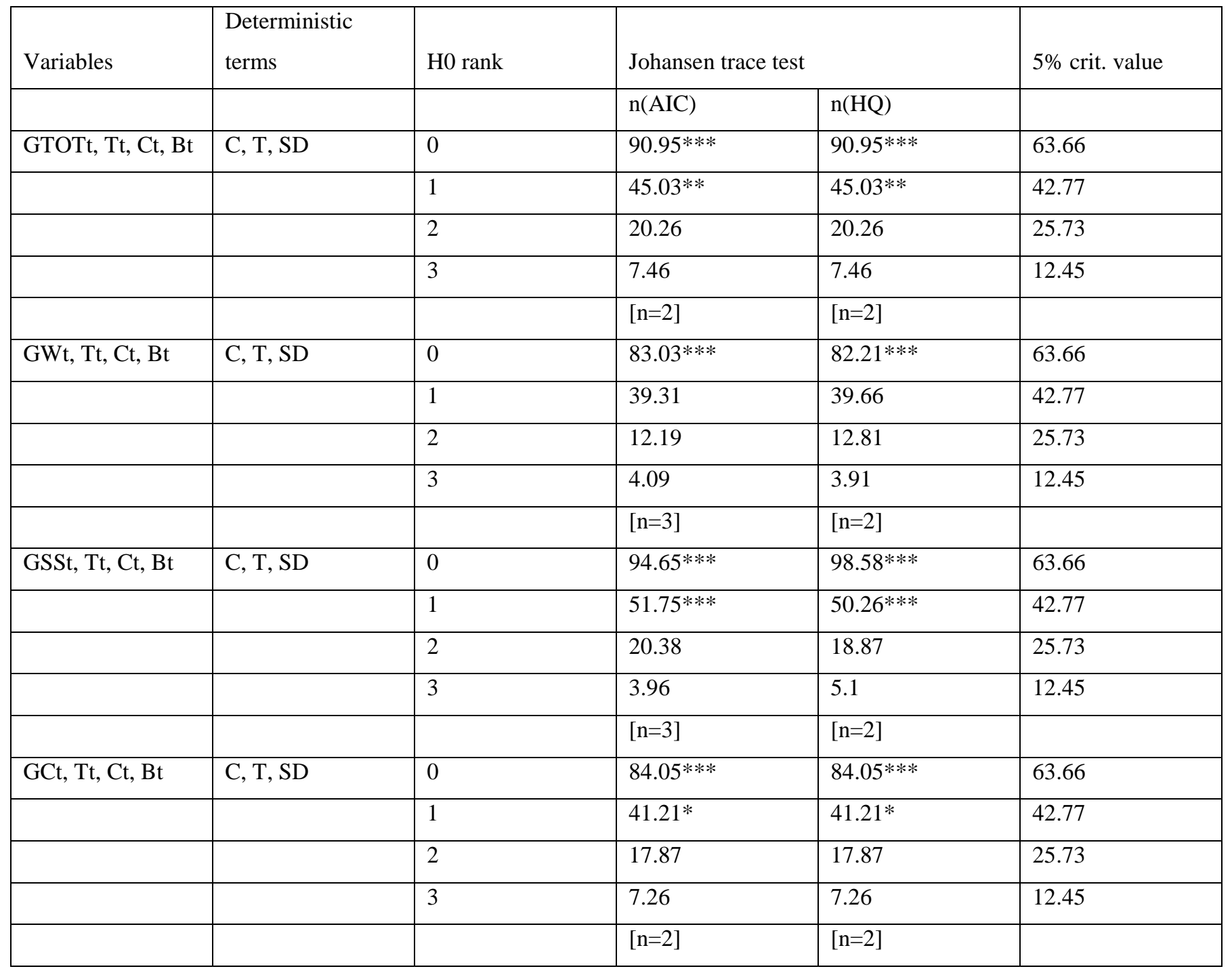

Notes: c - constant, $\mathrm{t}$ - linear time trend, sd - seasonal dummies. n(AIC) and n(HQ) indicate that the lag orders are chosen by the AIC and HQ criterion, respectively, with maximum lag order set to 8. The actual orders are given in brackets underneath the test values. $* * *$ and $* * *$ indicate that the null hypothesis can be rejected at the $10 \%, 5 \%$ and $1 \%$ levels, respectively, based on the critical values from Johansen (1995). 
Table 3. Estimated cointegrating matrix $\beta$ and loading coefficients

\begin{tabular}{|l|l|l|l|l|l|}
\hline Specification & \multicolumn{4}{|l|}{ Loading coefficients } & Fiscal Rules \\
\hline & $\alpha_{1 C}$ & $\alpha_{1 T}$ & $\alpha_{1 G}$ & $\alpha_{1 B}$ & \\
\hline$G=G T O T$ & $\alpha_{2 C}$ & $\alpha_{2 T}$ & $\alpha_{2 G}$ & $\alpha_{2 B}$ & \\
\hline & - & $-0.33^{*}$ & - & $-0.08^{* *}$ & $T_{t}=0.19 G_{t}+0.24^{* * *} B_{t}$ \\
\hline$G=G W$ & $0.00^{* * *}$ & $-0.22^{* *}$ & $0.00^{* * *}$ & $-0.64^{* * *}$ & $C_{t}=-0.12 G_{t}-0.12^{* * *} B_{t}$ \\
\hline & $0.02^{*}$ & $-0.36^{* * *}$ & $0.04 *$ & -0.08 & $T_{t}=0.67 * * * G_{t}+0.26^{* * *} B_{t}$ \\
\hline$G=G S S$ & $0.11^{* * *}$ & $-0.24^{* *}$ & - & $-0.60^{* * *}$ & $C_{t}=-0.30^{* * *} G_{t}-0.14^{* * *} B_{t}$ \\
\hline & - & $-0.49^{* * *}$ & $0.04^{*}$ & $0.18^{* * *}$ & $T_{t}=-0.41^{* * *} \underline{\mathrm{G}}_{t}+0.31^{* * *} B_{t}$ \\
\hline$G=G C$ & $0.00^{* * *}$ & $-0.56^{* * *}$ & -0.03 & $-0.18^{* * *}$ & $C_{t}=0.20^{* * *} G_{t}-0.17^{* * *} B_{t}$ \\
\hline & - & $-0.35^{* * *}$ & -0.03 & - & $T_{t}=0.09 G_{t}+0.25^{* * *} B_{t}$ \\
\hline & $0.07 * *$ & $-0.26^{* * *}$ & 0.01 & $-0.53 * * *$ & $C_{t}=-0.07 G_{t}-0.12^{* * *} B_{t}$ \\
\hline
\end{tabular}

Notes: $*, * *$ and $* * *$ indicate that the null hypothesis can be rejected at the $10 \%, 5 \%$ and $1 \%$ levels, respectively. 


\section{Appendix}

\section{Variables construction and data sources}

We use UK quarterly data for the period from the first quarter of 1981 to the fourth quarter of 2007. The variables are the following, all taken from the OECD Economic Outlook no. 83.

Government consumption GC: natural logarithm of (government final non-wage consumption expenditure + general government other current disbursements) deflated by the government final consumption expenditure deflator.

Government wage expenditure GW: natural logarithm of government final wage consumption expenditure deflated by the government final consumption expenditure deflator.

Government net social security benefits GSS: natural logarithm of cyclically adjusted (social security benefits paid by general government + subsidies - social security contributions received by general government) deflated by the government final consumption expenditure deflator.

Total government spending GTOT: natural logarithm of the sum of the three components.

Taxes: natural logarithm of cyclically adjusted (total direct taxes + total indirect taxes) deflated by the GDP deflator.

Private consumption $C$ : natural logarithm of private final consumption expenditure deflated by the private final consumption expenditure deflator.

Government debt B: natural logarithm of general government net financial liabilities deflated by the GDP deflator.

Table A1: some descriptive statistics.

\begin{tabular}{|llllll|}
\hline Variable & No. of obs. & Mean & Std. Dev. & Min. value & Max. value \\
\hline GTOT & 108 & 12.601 & 0.136 & 12.395 & 12.843 \\
$G W$ & 108 & 11.618 & 0.071 & 11.526 & 11.774 \\
$G C$ & 108 & 11.706 & 0.239 & 11.402 & 12.170 \\
GSS & 108 & 11.039 & 0.190 & 10.550 & 11.380 \\
$T$ & 108 & 11.886 & 0.198 & 11.541 & 12.247 \\
$B$ & 108 & 12.420 & 0.427 & 11.660 & 12.961 \\
$C$ & 108 & 13.205 & 0.242 & 12.792 & 13.599 \\
\hline
\end{tabular}


VECM estimates (four models according to the different public spending variable)

Table A2: total government spending (GTOT) model

\begin{tabular}{|c|c|c|c|c|}
\hline & $\Delta C_{t}$ & $\Delta T_{t}$ & $\Delta G T O T_{t}$ & $\Delta B_{t}$ \\
\hline$e c 1_{t-1}$ & $0.000(4.561)$ & $-0.224(-2.117)$ & $0.001(7.652)$ & $-0.642(-6.120)$ \\
\hline $\mathrm{ec} 22_{\mathrm{t}-1}$ & & $-0.325(-6.102)$ & & $-0.080(-1.727)$ \\
\hline$\Delta C_{t-1}$ & $0.203(2.650)$ & & $-0.366(-1.809)$ & $0.644(2.132)$ \\
\hline$\Delta C_{t-2}$ & $0.286(3.875)$ & & $-0.985(-5.163)$ & \\
\hline$\Delta C_{t-3}$ & & & $-0.335(-1.713)$ & \\
\hline$\Delta T_{t-1}$ & 0.055 (3.029) & $-0.308(-4.070)$ & $-0.083(-1.819)$ & \\
\hline$\Delta T_{t-2}$ & & & & \\
\hline$\Delta T_{t-3}$ & & & $-0.126(-2.760)$ & \\
\hline$\Delta G T O T_{t-1}$ & & & $-0.416(-4.768)$ & $-0.159(-1.432)$ \\
\hline$\Delta G T O T_{t-2}$ & $-0.093(-2.985)$ & & $-0.258(-3.041)$ & \\
\hline$\Delta G T O T_{t-3}$ & $-0.144(-4.607)$ & & & \\
\hline$\Delta B_{t-1}$ & $0.088(3.780)$ & $-0.152(-1.681)$ & & $0.574(7.336)$ \\
\hline$\Delta B_{t-2}$ & $-0.056(-2.353)$ & & & \\
\hline$\Delta \mathrm{B}_{t-3}$ & & $-0.287(-3.147)$ & & $-0.043(-0.558)$ \\
\hline
\end{tabular}

Notes: t-ratios in parenthesis. Estimates for deterministic terms (C, T, SD) not reported. 
Table A3: government wages $(G W)$ model

\begin{tabular}{|lllll|}
\hline & $\Delta C_{t}$ & $\Delta T_{t}$ & $\Delta G W_{t}$ & $\Delta B_{t}$ \\
\hline $\mathrm{ec} 1_{\mathrm{t}-1}$ & $0.111(4.076)$ & $-0.236(-2.536)$ & $-0.600(-6.725)$ \\
$\mathrm{ec} 2_{\mathrm{t}-1}$ & $0.021(1.666)$ & $-0.359(-6.477)$ & $0.038(1.705)$ & $-0.075(-1.581)$ \\
$\Delta C_{t-1}$ & & & $0.443(2.138)$ & $0.779(2.692)$ \\
$\Delta C_{t-2}$ & $0.181(2.049)$ & & $-0.480(-2.524)$ & \\
$\Delta C_{t-3}$ & & & $-0.076(-1.542)$ & $0.091(1.451)$ \\
$\Delta T_{t-1}$ & $0.041(2.145)$ & $-0.322(-4.263)$ & $-0.077(-1.441)$ & \\
$\Delta T_{t-2}$ & & & $-0.065(-1.305)$ & $-0.111(-1.789)$ \\
$\Delta T_{t-3}$ & & & $-0.558(-6.674)$ & \\
$\Delta G W_{t-1}$ & & & $-0.442(-5.174)$ & \\
$\Delta G W_{t-2}$ & $-0.069(-2.120)$ & & $-0.320(-3.850)$ & $0.261(2.593)$ \\
$\Delta G W_{t-3}$ & $-0.063(-1.967)$ & $-0.191(-1.558)$ & $0.591(7.991)$ \\
$\Delta B_{t-1}$ & $0.113(4.190)$ & $-0.159(-1.794)$ & & $-0.075(-0.984)$ \\
$\Delta B_{t-2}$ & $-0.030(-1.138)$ & & $-0.289(-3.189)$ & \\
$\Delta B_{t-3}$ & & & & \\
\hline
\end{tabular}

Notes: t-ratios in parenthesis. Estimates for deterministic terms (C, T, SD) not reported. 
Table A4: government net social security spending (GSS) model

\begin{tabular}{|lllll|}
\hline & $\Delta C_{t}$ & $\Delta T_{t}$ & $\Delta \mathrm{GSS}_{t}$ & $\Delta B_{t}$ \\
\hline $\mathrm{ec} 1_{\mathrm{t}-1}$ & $0.000(3.938)$ & $-0.541(-5.938)$ & $-0.034(-1.581)$ & $-0.178(-7.753)$ \\
$\mathrm{ec} 2_{\mathrm{t}-1}$ & & $-0.494(-7.171)$ & $0.040(1.772)$ & $0.181(7.758)$ \\
$\Delta C_{t-1}$ & $0.195(2.429)$ & & $-2.147(-3.221)$ & \\
$\Delta C_{t-2}$ & $0.253(3.272)$ & $0.643(1.794)$ & $-2.792(-4.269)$ & \\
$\Delta C_{t-3}$ & & & $-1.559(-2.410)$ & \\
$\Delta T_{t-1}$ & $0.049(2.601)$ & $-0.229(-2.979)$ & & \\
$\Delta T_{t-2}$ & & & $-0.572(-3.825)$ & $-0.135(-2.284)$ \\
$\Delta T_{t-3}$ & & & $-0.295(-3.324)$ & $-0.087(2.532)$ \\
$\Delta G S S_{t-1}$ & & $0.057(1.342)$ & $-0.229(-2.726)$ & $-0.056(-1.678)$ \\
$\Delta G S S_{t-2}$ & $-0.026(-2.645)$ & & & $0.530(9.521)$ \\
$\Delta G S S_{t-3}$ & $-0.028(-2.866)$ & & & \\
$\Delta B_{t-1}$ & $0.097(3.959)$ & & & \\
$\Delta B_{t-2}$ & $-0.061(-2.504)$ & & $-0.349(-4.066)$ & \\
$\Delta B_{t-3}$ & & & & \\
\hline
\end{tabular}

Notes: t-ratios in parenthesis. Estimates for deterministic terms $(C, T, S D)$ not reported. 
Table A5: government purchases of goods and services $(G C)$ model

\begin{tabular}{|lllll|}
\hline & $\Delta C_{t}$ & $\Delta T_{t}$ & $\Delta \mathrm{GC}_{t}$ & $\Delta B_{t}$ \\
\hline $\mathrm{ec}_{\mathrm{t}-1}$ & $0.066(2.425)$ & $-0.252(-2.537)$ & $0.028(2.348)$ & $-0.532(-6.395)$ \\
$\mathrm{ec} \mathrm{t}_{\mathrm{t}-1}$ & & $-0.348(-6.637)$ & $-0.055(-2.271)$ & \\
$\Delta C_{t-1}$ & $0.166(1.906)$ & & & $0.591(2.063)$ \\
$\Delta C_{t-2}$ & $0.225(2.634)$ & & $-0.566(-1.928)$ & \\
$\Delta C_{t-3}$ & & & & \\
$\Delta T_{t-1}$ & $0.052(2.748)$ & $-0.315(-4.217)$ & & \\
$\Delta T_{t-2}$ & & & & \\
$\Delta T_{t-3}$ & & & $-0.429(-4.732)$ & \\
$\Delta G C_{t-1}$ & & & $-0.223(-2.475)$ & \\
$\Delta G C_{t-2}$ & & & & \\
$\Delta G C_{t-3}$ & $-0.061(-2.847)$ & & & \\
$\Delta B_{t-1}$ & $0.112(4.298)$ & $-0.163(-1.831)$ & & \\
$\Delta B_{t-2}$ & $-0.064(-2.593)$ & & & \\
$\Delta B_{t-3}$ & & & & \\
\hline
\end{tabular}

Notes: t-ratios in parenthesis. Estimates for deterministic terms (C, T, SD) not reported.

Table A6: diagnostics

\begin{tabular}{|lccccc|}
\hline & Portmanteau test (24 lags) & \multicolumn{5}{c|}{ LM test for autocorrelation } \\
\hline & & 1 lag & 2 lags & 4 lags & 8 lags \\
GTOT model & 0.768 & 0.973 & 0.941 & 0.913 & 0.534 \\
GW model & 0.453 & 0.862 & 0.913 & 0.368 & 0.112 \\
GSS model & 0.684 & 0.889 & 0.802 & 0.705 & 0.836 \\
GC model & 0.923 & 0.976 & 0.997 & 0.89 & 0.628 \\
\hline
\end{tabular}

Notice: p-values are reported in the table (adjusted p-values for the Portmanteau test). 
Table A7: estimated $A$ and $C(1) A$ matrices

\begin{tabular}{|c|c|c|c|c|c|c|c|}
\hline \multicolumn{4}{|c|}{ Matrix $A$} & \multicolumn{4}{|c|}{ Matrix $C(1) A$} \\
\hline$C$ & $T$ & GTOT & $B$ & $C$ & $T$ & GTOT & $B$ \\
\hline $0.001(3.220)$ & $0.000(-0.811)$ & $0.000(3.559)$ & $-0.005(-1.080)$ & $-0.000(-6.051)$ & 0 & 0 & $-0.008(-1.079)$ \\
\hline$-0.002(-0.910)$ & $0.021(8.837)$ & $0.011(2.284)$ & $-0.001(-0.321)$ & $0.002(6.051)$ & 0 & 0 & $0.016(1.079)$ \\
\hline $0.013(6.787)$ & 0 & $0.000(3.884)$ & $0.003(0.889)$ & $0.009(6.051)$ & 0 & 0 & $0.008(1.052)$ \\
\hline $0.000(0.160)$ & $0.005(1.721)$ & $-0.019(-7.205)$ & $0.002(0.960)$ & 0 & 0 & 0 & $0.061(1.079)$ \\
\hline \multicolumn{4}{|c|}{ Matrix $A$} & \multicolumn{4}{|c|}{ Matrix $C(1) A$} \\
\hline$C$ & $T$ & $G W$ & $B$ & $C$ & $T$ & $G W$ & $B$ \\
\hline $0.001(1.859)$ & $-0.003(-2.313)$ & $-0.001(-0.942)$ & $0.005(2.548)$ & $0.002(2.625)$ & 0 & 0 & $0.010(2.118)$ \\
\hline$-0.006(-1.418)$ & $0.006(2.153)$ & $-0.021(-2.427)$ & $0.001(0.164)$ & $-0.004(-2.625)$ & 0 & 0 & $-0.018(-2.109)$ \\
\hline$-0.014(-2.705)$ & 0 & $0.003(1.844)$ & $0.002(1.205)$ & $-0.006(-2.625)$ & 0 & 0 & $0.004(1.820)$ \\
\hline $0.001(0.222)$ & $0.015(3.637)$ & $0.008(1.860)$ & 0.009 (2.309) & 0 & 0 & 0 & $-0.078(-2.150)$ \\
\hline \multicolumn{4}{|c|}{ Matrix $A$} & \multicolumn{4}{|c|}{ Matrix $C(1) A$} \\
\hline$C$ & $T$ & $G S S$ & $B$ & $C$ & $T$ & $G S S$ & $B$ \\
\hline $0.003(6.524)$ & $0.000(-2.368)$ & $0.000(-1.629)$ & $-0.005(-0.810)$ & $0.003(7.859)$ & 0 & 0 & $-0.006(-0.817)$ \\
\hline$-0.002(-1.071)$ & $0.022(9.158)$ & $-0.005(-1.546)$ & $-0.002(-0.611)$ & $-0.006(-7.859)$ & 0 & 0 & $0.011(0.816)$ \\
\hline $0.038(9.383)$ & 0 & $0.004(1.940)$ & $0.024(0.757)$ & $0.015(7.859)$ & 0 & 0 & $0.045(0.804)$ \\
\hline$-0.003(-1.276)$ & $0.001(0.242)$ & $0.018(1.957)$ & $0.000(0.228)$ & 0 & 0 & 0 & $0.094(0.812)$ \\
\hline \multicolumn{4}{|c|}{ Matrix $A$} & \multicolumn{4}{|c|}{ Matrix $C(1) A$} \\
\hline$C$ & $T$ & $G C$ & $B$ & $C$ & $T$ & $G C$ & $B$ \\
\hline $0.000(0.780)$ & $-0.002(-2.075)$ & $0.002(1.903)$ & $0.005(1.333)$ & $0.001(0.852)$ & 0 & 0 & $0.010(1.487)$ \\
\hline $0.008(0.859)$ & $0.011(3.995)$ & $0.019(3.777)$ & $-0.001(-0.486)$ & $-0.001(-0.852)$ & 0 & 0 & $-0.020(-1.489)$ \\
\hline$-0.022(-0.847)$ & 0 & $0.005(2.436)$ & $0.001(0.180)$ & $-0.015(-0.852)$ & 0 & 0 & $-0.005(-1.095)$ \\
\hline$-0.004(-0.875)$ & $0.014(6.386)$ & $-0.012(-3.129)$ & $0.006(1.762)$ & 0 & 0 & 0 & $-0.078(-1.494)$ \\
\hline
\end{tabular}

Notes: t-ratios in parenthesis. Standard errors are bootstrapped (500 replications). 


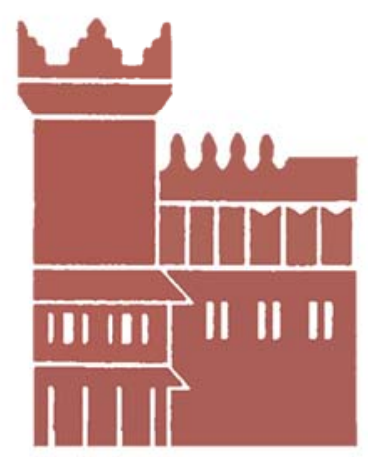

Alma Mater Studiorum - Università di Bologna DEPARTMENT OF ECONOMICS

Strada Maggiore 45

40125 Bologna - Italy

Tel. +39051 2092604

Fax +390512092664

http://www.dse.unibo.it 